\title{
The Claims and Duties of Socioeconomic Human Rights
}

word count (including abstract, notes, and reference list): 9,911

\begin{abstract}
A standard objection to socioeconomic human rights is that they are not claimable as human rights: their correlative duties are not owed to each human, independently of specific institutional arrangements, in an enforceable manner. I consider recent responses to this 'claimability objection,' and argue that none succeeds. There are no human rights to socioeconomic goods. But all is not lost: there are, I suggest, human rights to 'socioeconomic consideration.' I propose a detailed structure for these rights and their correlative duties, while remaining neutral on substantive moral debates. I argue that socioeconomicconsideration human rights are satisfactorily claimable and sufficiently practical.
\end{abstract}

\section{The Claimability Problem}

Hundreds of millions of people in our world lack reliable access to basic socioeconomic goods. That is, they lack reliable access to the goods necessary for attaining and foreseeably maintaining a minimally decent human life. We can safely assume these include some level of food, water, shelter, clothing, medical care, education, and social interaction (Gilabert 2009, 659; Brownlee 2013). In a world where some have all the socioeconomic goods they could possibly want, this is deeply troubling.

But is it a human rights violation? To answer this, we need to know whether there are human rights to socioeconomic goods. Some philosophers think there are not, because such rights are not 'claimable.' I shall focus on this claimability problem. In general, a right is claimable just in case there is one or more specific agent with a duty, owed to the claimant, to see to it that the full content of the right is realised. The agent(s) wrongs the claimant if the 
agent(s) does not do this. Contents of rights might be things like 'the agent meets the claimant at the promised time' or 'the agents do not physically abuse the claimant.'

I will assume that human rights have two further conditions on their claimability. First, the agent(s) owe the performance independently of specific institutional arrangements. This is arguably necessary for rights to be genuinely human rights: rights borne simply in virtue of being a human, in a world with at least one moral agent. And, by most accounts, this condition is necessary for a 'naturalistic' or 'practice-independent' conception of human rights, as opposed to a 'political' or 'practice-dependent' one. Roughly, the former takes its cue from moral theory, while the latter takes its cue from human rights practice since 1945. Some think the claimability problem mandates a shift to a political conception (Tomalty 2014). Others advocate alternative naturalistic conceptions, on which claimability is not an existence condition of a right (Tasioulas 2007; 2010). I want to see if we can salvage naturalistic, claimable human rights to socioeconomic goods.

The second human-rights-specific claimability condition derives from the importance of human rights' contents. This importance implies that the rights should be enforceable. Enforceability denotes two things. First, if your human right has been violated, you (or your representative) are permitted to extract redress, compensation, and perhaps punishment. Second, if your human right is about to be violated, you (or your representative) are permitted to impose costs on the would-be violator to prevent this. The high importance of the contents of human rights implies that their claimability should have actionable teeth. Enforceability gets us this.

Combining these three conditions, I will assume the claimability of a socioeconomic good as a human right entails three things: 
(i) each human is owed the socioeconomic good from one or more agents, so the agent(s) wrong that human if the agent(s) does not see to it that the human has the socioeconomic good [general notion of rights-claimability]; and

(ii) each human is owed the socioeconomic good independently of specific institutional arrangements [requirement for naturalistic human rights]; and

(iii) each human (or his/her representative) may use threat or coercion to extract the socioeconomic good from the agent(s) [requirement for teeth].

Why are socioeconomic goods thought to be unclaimable in this sense? Because 'ought' implies 'can.' In light of (i), notice that no actual moral agent, whether individual or collective, can provide any socioeconomic good to all vulnerable humans. So, assuming 'ought' implies 'can,' no agent owes any socioeconomic good to every human.

Instead, perhaps each agent owes these goods to some subset of people (say, the agent's family). Such rights would not meet any of the three conditions for claimability as a human right: these conditions refer to each human, and not all humans are guaranteed to have living family (or other special relationship-holders) who can give them the goods. So this is no way to produce human rights. Or perhaps each agent enjoys some discretion over how to discharge whatever duties they have with regard to socioeconomic goods. Each agent might choose to provide the goods to some subset of vulnerable humans who the agent picks, or each agent owes some tiny amount of each good to every vulnerable human. On this possibility, no agent wrongs any vulnerable human if that agent chooses to discharge her duty in a way that provides adequate food for someone other than that human, and threat or coercion cannot be used by any human to extract adequate food from any agent. At least, that's true until some agent is somehow 'picked out' by specific institutional arrangements as owing that vulnerable human adequate food. But that would violate condition (ii). In other 
words, as long as (i) and (ii) are both required for claimability, socioeconomic goods are not claimable as human rights. (Gilabert 2009, 659; Hope 2014, 8; O’Neill 1996, 330-2; O’Neill 2005, 431-2.)

One might think claimability is also problematic for civil-political human rights. ${ }^{1}$ There is dispute about the moral significance of the distinction between socioeconomic and civil-political human rights (Lichtenberg 2004; Shue 1996, ch. 2; OHCHR 2015). In general, though, civil-political rights relate to non-interference and to procedural recognition, while socioeconomic rights relate to goods and services. There are two reasons why I shall focus on socioeconomic rights.

The first is that the contents of some civil-political rights—such as a fair trial or political participation - arguably depend on specific institutions (in particular, modern states) (Beitz 2003). If specific institutional arrangements are smuggled into the very contents of human rights, we can use these arrangements to 'pair up' right-holders with duty-bearers, including assigning 'back-up' duty-bearers in case the primary duty-bearers renege (as Nickel (1993, 82-3; 2005) does). The claimability problem is thus easily 'solved'-but at the expense of condition (ii). Only a political conception of these human rights would be possible.

However, perhaps political rights are fundamentally institution-independent. (Griffin $(2008,50)$ suggests this; Tasioulas $(2012,31-6)$ disputes it.) For example, maybe 'political participation' means not 'a vote in free and fair elections', but more broadly 'having input into decisions about social arrangements'. The former is simply a contextually-appropriate specification of the latter. If this is correct, then condition (ii) is not violated and the claimability problem will arise for these rights. However, I lack space to defend a broad conception of these political rights, so will put their claimability to one side. By contrast,

\footnotetext{
${ }^{1}$ I thank an anonymous referee for suggesting this.
} 
having 'adequate food' or 'adequate education' doesn't require specific institutional arrangements.

The second reason for focusing on socioeconomic rights is that other civil-political rights—-such as the right against torture or to free speech—in the first instance require only non-interference. This poses no problems for claimability, since non-interference can be claimed against each agent at all times. Now, if some agent does interfere or is about to interfere, then the right-holder might have a second-instance claim that third parties intervene to protect the right-holder-that is, a claim for protection, additional to the right-holder's permission to protect herself that was posited in condition (iii). ${ }^{2}$ These second-instance protection claims face the claimability problem: protection is expensive, so cannot be given to all humans by any one agent. But this does not undermine the first-instance claimability of non-interference rights: the right against interference is still claimable by each human against each who can interfere, even if it may not be claimable against those who can protect against interference. Socioeconomic human rights, however, seem not to be claimable against anyone at all, not even in the first instance, since they require positive action in the first instance (in a world without overabundance) (O’Neill 2000, 105). Thus, the claimability problem looms larger for socioeconomic rights, even if it also looms for the (perhaps non-existent) protection aspect of non-interference rights.

All that said, it remains possible that there are civil-political rights that neither require particular institutions, nor demand only non-interference in the first instance. If so, all the arguments of this paper apply to those civil-political rights, though I will not discuss them explicitly.

The argument begins in §II by considering several recent attempts to solve the claimability problem. Perhaps coercive institutions owe socioeconomic goods to all persons

\footnotetext{
${ }^{2}$ Waldron (1993, 212-3) and Shue (1996) argue there is such a claim; Locke implies not (1689, essay 2, ch. 2), though Steiner (2006) argues such claims are at least consistent with Lockean self-ownership.
} 
they coerce (Pogge 2002). Or perhaps humanity has a group-level duty to provide socioeconomic goods for all (Ashford 2006; Nussbaum 2004; Waldron 1993; Wringe 2005). Or perhaps what is claimable is that each agent considers socioeconomic human rights in their deliberations (Sen 2004; Gilabert 2009). I argue that none of these succeed in vindicating a claimable human right to socioeconomic goods. But the last suggestion gives us the seeds of a claimable human right that is grounded in the value of socioeconomic goods. The idea is that each human—in virtue of being human—bears claimable rights (one right for each pairing of a socioeconomic good and an agent) that each agent conducts equitable deliberation and action for respecting, protecting, and promoting the socioeconomic good. I call these 'socioeconomic-consideration human rights.'

The rest of the article gives precision to this idea. $\S$ III details a proposed structure for socioeconomic-consideration human rights and their correlative duties. Importantly, the proposed structure aims at neutrality between competing ways of decorating the structure with substantive value theories. This neutrality will allow us to retain the structure, and so retain socioeconomic-consideration human rights, regardless of how substantive debates are resolved. §IV argues that socioeconomic-consideration human rights are satisfactorily claimable and sufficiently practical.

\section{Existing Solutions to the Claimability Problem}

\section{II.A Claimable against a Group Agent}

An initially attractive solution to the claimability problem asserts that all socioeconomic human rights are claimable by each human against the dominant social institution under which that human lives. So, (i) such institutions wrong each human living under them, if the human does not enjoy a socioeconomic good; and (iii) each human (or his/her representative) 
may use threat or coercion to extract socioeconomic goods from the institution. Initially, this may seem to violate (ii): the rights seem dependent on specific institutional arrangements. But the solution doesn't lean upon any specific institutional arrangements. It just requires that we allow some social institution into the picture. This solution would assert that human rights were held in tribal societies before their contact with Europe, for example. This solution potentially chimes with Thomas Pogge's view that human rights are claims that coercive social institutions have certain rules and norms $(2002,50-3,63-8,70,73) .^{3}$

There is a constraint on this solution: the institutions must be agents. After all, the duties correlative to socioeconomic human rights are duties to see to it that something obtains. If 'seeing to it that $\mathrm{X}$ ' is an action (which it seems to be), then it can be performed only by an agent. As Holly Lawford-Smith puts it, "[a]ttributing obligations to [non-agent] groups makes those obligation statements impotent: it requires action from something that cannot act." (Lawford-Smith forthcoming, 226) Non-agent groups cannot act for one or both of two reasons: first, they cannot will, intend, or try, since they lack the necessary group-level reasoning apparatus; and second, in most contexts, there is an insufficiently high likelihood of the non-agent group bringing about the end that the 'action' would achieve, even if each individual in the non-agent group were to try to bring about that end (Collins 2013; LawfordSmith forthcoming). This is why the three conditions for claimability refer to 'agents,' not simply 'duty-bearers.'

So the relevant institutions must be agents. This is not damning: on popular views of group agency, any group with a group-level rational decision-making procedure counts as an agent (French 1979; List and Pettit 2011). Most states have such procedures (Wendt 2004). Probably, so do councils, chieftainships, groups of hunter-gatherers, and other long-term cooperative social groups: it's unlikely such groups would survive without group-level

\footnotetext{
${ }^{3}$ Pogge says these rights "ultimately make demands upon" individuals who are "collectively responsible" for the institutions $(2002,70,178-9)$. This reductionism is disputable. Here I focus on the institutions as dutybearers. Shared duties of upholders come under §III.B's discussion.
} 
rational decision-making procedures. So, each person's socioeconomic human rights might be claimable against such an entity.

A question for this solution is whether one's socioeconomic human rights are claimable only against one's dominant social institution. On the one hand, if so, this violates “ought' implies 'can'? there is not always an institutions capable of fulfilling a given human's socioeconomic human rights (Cranston 1962, 41). ${ }^{4}$ Take the right to adequate healthcare in Gaza. Is there any one social institution that can fulfil this right? Perhaps Hamas can. But their ability is questionable, given the role Egypt and Israel play in controlling Gaza's border (and, therefore, the healthcare equipment that must come across that border). If no one agent can provide Gazans with adequate healthcare, then no agent can have a duty to do so. Even if Hamas can in fact fulfil Gazans' human right to adequate healthcare, still: if it could not, other agents would have a human rights-based duty to create a capable agent (Pogge 1992; Kuper 2000; Cabrera 2004). These latter duties cannot be borne by the institutions itself since, ex hypeothesi, no institution exists that is capable of such self-reform. The 'institution' solution cannot generate the duties that intuitively exist in cases of groupagent break-down.

On the other hand, suppose Gazans' socioeconomic human rights are claimable against each of Hamas, Israel, and Egypt. Suppose, more generally, that one's socioeconomic human rights are claimable against agents including, but not limited to, one's dominant social institution. We then run straight back into the claimability problem: without a 'joining up' of agents and claimants imposed by specific institutional arrangements, no agent owes any particular Gazan any socioeconomic good. This is because, without specific institutional arrangements, it is unclear why each agent doesn't also owe the goods to every other human—but then that would violate 'ought' implies 'can'.'

\footnotetext{
${ }^{4}$. Pogge considers this, and therefore describes the right to basic necessities as a right that social institutions "reduce insecurity of access to basic necessities." $(2002,74)$ This re-description is damning to a human right to socioeconomic goods.
} 
The problem here is not just that it's difficult for the numerous duty-bearing agents to coordinate. The problem is that each agent's duty cannot literally be a duty to ensure humans have adequate socioeconomic goods, because no agent can do this on their own (at least in contexts like Gaza). Making this happen takes coordination. But agents cannot coordinate unilaterally. So, assuming no agent can force the others to coordinate (thereby ensuring, unilaterally, that all humans get the goods), no agent owes the humans the goods. Perhaps each agent owes each human some help in getting the goods, or should try to coordinate with other agents to secure the goods-in fact, §III will suggest something like this. But this is not a duty to ensure the human has the goods (as distinct from trying to secure the goods or attempting to coordinate), since no agent can do that on their own. But if no agent has a duty to see to it that the human has the goods, then there can be no right to the goods: this follows from condition (i) for claimability.

\section{II.B Claimable against a Non-agent Group}

If we could resist the idea that each duty is held by an agent, then socioeconomic human rights could be claimable against a non-agent group, as a singular entity. Several philosophers have made this move. Elizabeth Ashford suggests that in some cases "we can say that a group of agents is responsible for a large number of human rights violations, but we cannot single out the perpetrator of a particular victim's right violation" (2006, 219). Martha Nussbaum views "humanity" as bearing a collective obligation to provide people with basic capabilities (2004, 13). Pogge says that "persons involved in upholding coercive social institutions [possibly, all persons] have a shared moral responsibility" (2002, 55, emphasis added). Jeremy Waldron asserts each "indigent" has "a right against all the possible sources of charity taken together" $(1993,16)$. Leif Wenar thinks socioeconomic human rights are claimable against "the international community" (2007, 273-4). And Bill Wringe argues that 
the right to subsistence places a duty on the group constituted by all of humanity (2005; forthcoming).

Above, I gave two reasons why we should resisting attributing duties to non-agents. These reasons apply to 'humanity' and 'the affluent': these groups cannot act, since they lack group-level rational decision-making procedures, and they are unreliable. But even putting these reasons to one side, we should still resist this solution. This is because it doesn't satisfactorily live up to conditions (i) and (iii) for claimability.

On (i), it is often inaccurate to say "all of humanity" or "the affluent" wrongs a person if that person doesn't enjoy socioeconomic goods. To see this, suppose some people play their part—or even take up others' slack—in the alleged collective obligation. But, suppose, there are enough slackers that not all humans enjoy socioeconomic goods. It would then be incorrect to paint the compliers-let alone the slack-takers-with the "wronger" brush. The wronging is more specific: it's performed by only some people in the collective, and should be acknowledged as such. But if we are going to individualise wronging, then it seems bizarre not to individualise the duties to which the wronging relates.

On (iii), it is unclear what kind of force or coercion could possibly be used against "all of humanity" or "the affluent." On the one hand, if the coercion must be applied to all people in the group, then enforcement of socioeconomic human rights becomes materially impossible for most humans (and their representatives). On the other hand, if the coercion may be applied to only a subset of group, then coercion is possible-but we then need some method of choosing which subset is to be coerced. This requires considering the attributes of the individual agents in the group, and so ignoring the idea that the duty belongs to the group itself. Again, if we individualise coercion, we should individualise the duties to which the coercion relates. 
Still, perhaps the virtues of this solution outweigh the costs. One alleged virtue is explanatory power. Suppose you and I could save a drowning toddler, if only we coordinated. Wringe would argue that your duty to take individual steps towards coordinating with me can be explained only with reference to a group-level duty to save the toddler; thus, we should posit group-level duties borne by the non-agent group composed of you and me (2005, 202-3; forthcoming). However, the individuals' duties-to-take-steps-towards-coordinating can be explained just as well with reference to the fact that, if each of us takes individual steps towards coordination, then there is a sufficiently high likelihood that the other will do likewise and that a highly valuable outcome (the toddler's being saved) will be realised. An explanation of the individual duties can be found simply in the value of the individual actions, which (in this example) derive from the value of the state of affairs each individual action will probably realise. There's no explanatory need for group-level duties of a nonagent group.

In sum, to view a non-agent group as the bearer of duties to fulfil human rights is to misfire on the issues of action, reliability, wrongdoing, enforceability, and explanatory power. So we should also resist viewing individuals' duties as parts of a duty held by a nonagent group. Importantly, though, these points do not apply to group agents. Group agents can act, can act reliably, and many of their actions, duties, and wrongings cannot be reduced to analogous facts about individuals (Pettit 2007; List and Pettit 2011).

\section{II.C Claimable against Each Agent}

A third solution views the duties correlative to socioeconomic human rights as owed to each human by each (individual or group) agent. Amartya Sen-briefly and in passing — suggests the duties correlative to human rights are duties to give "reasonable consideration" to what one might do to respect, protect, and fulfil the right. Sen admits this is loose, and suggests 
"[t]he demands of reasonable consideration would vary with a great many parameters that may be relevant to a person's practical reasoning." (Sen 2004, 339) These parameters include "how important the freedoms and rights are in the case in question compared with other claims on the person's possible actions"; "the extent to which he or she can make a difference in this case, either acting alone or in conjunction with others"; and "what others can be expected to do, and the appropriateness of how the required supportive actions may be shared among possible agents.” (2004, 339-40)

Similarly, Pablo Gilabert suggests socioeconomic human rights impose "a duty of the highest priority for individuals and governments to identify ways to protect certain important interests through (a) specific rights and entitlements, but also, when these are insufficient or not presently feasible, through (b) urgent goals of institution-building." (Gilabert 2009, 673) Elsewhere, Gilabert states "I do not think that any full determination of such duties can be provided in abstracto." Still, he hints at how agents might proceed: "We need to identify what the basic needs to be met are and who has them, who can contribute to their satisfaction without engaging in unreasonable sacrifice, how to set up schemes of regular mutual assistance, and how to secure that such mechanisms are under the ultimate control of those who are supposed to act on their basis." $(2010,397)$ Before these schemes and mechanisms are established, agents' duties contain latitude $(2010,399) .^{5}$

A first problem is that these proposals do not vindicate human rights to socioeconomic goods. If duties are to "give reasonable consideration" or "identity ways", then the rights are to receive reasonable consideration or have the agent identify ways. If everyone owes me reasonable consideration or identification of means, but no one owes me socioeconomic goods, then it is not true that I am wronged if I don't have socioeconomic

\footnotetext{
${ }^{5}$ Sen and Gilabert are not alone, though they elaborate the most. Brownlee says similar about the human right against social deprivation $(2013,219)$. Likewise Tasioulas, when discussing the human right against poverty $(2007,91)$. Pogge suggests similar, though it's not his most common formulation $(2002,75)$. These authors' proposals face the two problems outlined below for Sen and Gilabert. Tasioulas acknowledges this, so gives up on claimability $(2007,101)$.
} 
goods or that I may force others to provide me with them. James Griffin sums this up in the maxim that "[t]he content of a human right is also the content of the corresponding duty." $(2008,97)$

A second problem is that the duties are "loosely specified" (Sen 2004, 341) or contain "latitude" (Gilabert 2010, 399). This suggests each agent has discretion about which actions result from their consideration or identification of means. The claimability problem has then not been satisfactorily solved. What persons are owed, and can claim, is insufficiently certain and specific. So, what agents can be coerced into doing, and wrong people by not doing, is also insufficiently certain and specific. As James Nickel put it, "[r]ights are more definite than goals; they specify who is entitled to receive a certain mode of treatment (the rightholders) and who must act on specific occasions to make that treatment available (the addressees)" (1987, 17, emphasis added).

The tentative upshot of §II, then, is that human rights to socioeconomic goods are not claimable. ${ }^{6}$ That said, Sen's and Gilabert's proposals contain the seeds of a theoretically sound and morally satisfying solution to the claimability problem. There are two improvements to be made. First, we should admit that duties to give reasonable consideration correlate with rights to receive reasonable consideration, not rights to socioeconomic goods. Call these 'socioeconomic-consideration human rights'. This makes the solution theoretically sound. Second, we should specify 'reasonable consideration' so as to remove the discretion, as Sen and Gilabert do not. This makes the solution morally satisfying. The aim of the next section is to complete the second of these tasks.

\footnotetext{
${ }^{6}$ There are proposals I haven't discussed, e.g. Stemplowska's (2009) and Nickel's (1993, 82-3; 2005). In my view, Gilabert $(2009,672)$ successfully criticises the "sequential approach," which Nickel endorses, for not being independent of specific institutional arrangements. Stemplowska's proposed duties are not independent of particular acts of claiming.
} 


\section{Specifying the Duties}

\section{III.A The General Proposal}

One might think it impossible to be more specific than Sen or Gilabert: "there is no obvious index defining how much any person should justifiably sacrifice, in terms of her own distinct life aims, to secure the subsistence of the needy. Correspondingly, ... the level of entitlement for others is also unclear in this context" (Meckled-Garcia 2013, 79, 78; similarly Tasioulas 2007, 98). That is, because it is difficult to specify the right's content, one might assume the duty contains playroom, latitude, scope, or discretion (terms I use interchangeably). But this should not be the default position. Consider any analogy: the fact that philosophers disagree about what social justice demands does not lead us to give up attempting to specify those demands, and does not make us think that justice contains discretion. ${ }^{7}$ Yes, it is implausible that we can (at this point in philosophical history) stipulate that $10 \%$ of an affluent person's income must go toward furthering socioeconomic goods, rather than 20\% (Chappell ed. 2009; Feltham and Cottingham eds 2010). But we can do better than stating that the duties are to 'give consideration' or 'identify means.'

Concisely stated, my proposal is this: each human has a human right that each agent conducts equitable deliberation and action for respecting, protecting, and promoting socioeconomic goods. This brief formulation is similar to Sen's. But, more specifically:

For each socioeconomic good, each human has a claim on each moral agent (whether individual or collective) that:

(A) The agent undertakes epistemically reasonable deliberation and thereby forms an epistemically reasonable belief about which, if any, measure she should take to help further or secure the provision of that good for the claimant, and

\footnotetext{
${ }^{7}$ Gilabert (2010, 396-7) makes a similar point, though he does "not think that any full determination of such duties can be provided in abstracto"-
} 
(B) The claimant does not receive morally inequitable consideration in that deliberation, and

(C) If, in virtue of having completed (A) and (B), the agent reasonably believes she should take a measure to help further or secure the provision of the good for the claimant, then the agent acts with regard to the claimant as that measure dictates. (If, in virtue of having completed (A) and (B), the agent reasonably believes there is no good-furthering or good-securing measure she should take for the claimant, the duty is completed with (A) and (B).)

A different way of glossing it is this. Duties generated by the imperative that humans have socioeconomic goods are duties ultimately to take some socioeconomic measure, whether action or omission. 'Socioeconomic measures' are measures an agent reasonably believes will further or secure the provision of some socioeconomic good. So agent S's deliberation is aimed at figuring out which socioeconomic measure $\mathrm{S}$ should take, for a particular socioeconomic good. Call the socioeconomic measure that $\mathrm{S}$ should take, vis-a-vis a particular good, 'M'. Part (A) of S's duty is to form a belief, in an epistemically reasonable way, about which measure is M. If S doesn't undertake epistemically reasonable deliberation, she violates all humans' socioeconomic-consideration human rights. Part (B) of S's duty is to ensure no claimant receives morally inequitable consideration in that belief formation. $\mathrm{S}$ violates the socioeconomic-consideration human rights of anyone who receives inequitable consideration in her belief-formation. Part (B) allows $\mathrm{S}$ to use heuristics or other cognitive shortcuts: she need not consider each and every claimant by name. Such heuristics, one might think, do not treat each agent equitably. But, precisely because the heuristics don't make reference to any particular claimants, they also don't treat any claimant inequitably. This is why the double-negative in part (B) matters. Part (C) of S's duty is to actually take measure 
M. If she doesn't take measure $\mathrm{M}$, she violates the human rights of those whose provision of socioeconomic goods M would have helped to further or secure.

It is possible that, for some agent, there is no measure M. Thus the bracketed phrase in $(\mathrm{C})$ arises. This is because, in forming her epistemically reasonable and morally notinequitable belief (i.e., discharging parts (A) and (B) of the duty), S should abide by four conditions, which the next subsection lays out. It's possible that there is no measure with regard to which she can meet every condition. In this case, $S$ does her duty to all humans visa-vis that socioeconomic good just by doing the reasonable and not-inequitable deliberation and finding that there's no socioeconomic measure she should take for that particular good. But I will proceed on the assumption that, for each agent, there is some measure she should take to further each socioeconomic good. The next step is to do better than Sen, by making these duties non-discretionary.

\section{III.B Four Steps in Deliberation}

The task now is to make parts (A) and (B) of these duties non-discretionary, and so the rights claimable. I want to do this without taking a stand on substantive disputes about the limits of morality's demandingness, the relative importance of various human rights, the extent to which considerations such as community or contribution-to-harm affect our owings, and so on. One aim in this sub-section is to demonstrate that these duties can be action-guiding even in the face of moral uncertainty. A second aim is to demonstrate that we will be able to retain non-discretionary socioeconomic-consideration duties - and the claimable human rights with which they correlate-regardless of how philosophers end up settling substantive moral disputes. A third aim is to give an example of how these duties might be discharged for an actual agent. 
So, how should you go about discharging parts (A) and (B) of your duty? This requires appraising the socioeconomic measures open to you to determine which measure you ought to take. Measures might be one-off or short-term actions ("give $£ 50$ to Oxfam") or long-term patterns or policies of action ("follow party politics in your state, vote for whichever party seems likely to best further socioeconomic goods, and give $£ 20$ each month to socioeconomic goods-furthering charities"). To avoid worries about individuating measures, you should subject all measures to the same appraisal, no matter how conjunctive, diachronic, or dynamic those measures are. This does not require explicitly describing each measure: whole classes of measure can often be considered together, and many such classes can be ruled out after a moment's consideration. My suggestion for identifying M comes in four slogans: (1) Believe it'll help secure the socioeconomic good; (2) Don't do wrong; (3) Choose better over worse; (4) Randomise when unsure. Let me say a little to motivate and specify these.

First, consider that the point of the duty is to respond to the imperative that humans should have reliable access to a socioeconomic good. It's not to respond to some other moral imperative. So, plausibly, a necessary first condition for measure $\mathrm{M}$ is:

(1) For all agent $\mathrm{S}$ reasonably believes, $\mathrm{M}$ will bring some human(s) closer to having reliable access to the socioeconomic good.

A full discussion of 'reasonable belief' is beyond my scope here. But I do not assume that these epistemic duties are all-demanding. The requirement is for a reasonable belief, not an unassailable one. For example, suppose one socioeconomic good is education. Your beliefs about which measures will further education will probably be reasonable if you simply keep up with reliable new outlets, and periodically discuss your views with reflective friends. 
You don't violate others' human rights to education-consideration only if you take a measure that you reasonably believe will further education (assuming there is such a measure that also satisfies the other three slogans). Other actions might be good, but they wouldn't respond to that specific right. For example, you might reasonably believe you could further education by voting for an education-focused political party, or volunteering at an adult education programme, or donating money to a charity that cures children's intestinal worms. If so, these measures (and measures made up of the set or a sub-set of them) would meet condition (1).

A more precise version of slogan (2) is:

(2) S has a reasonable belief that S's taking M would not be wrong.

Some measures that pass slogan (1) might fail slogan (2). Suppose you reasonably believe that the only education-focused political party on your ballot card will focus on elite private schooling. This will help secure adequate education for rich children, so will pass slogan (1). However (you reasonably believe, the party will sharply cut public spending, which will strongly exacerbate poverty. You reasonably believe that it is wrong to contribute to, or symbolically indicate support of, the exacerbation of poverty. Voting for the educationfocused party fails slogan (2).

When it a measure wrong? Answering this requires resolving the substantive moral disagreements, about which my framework is neutral. Perhaps only some violationsviolations of 'justice', or of other human rights, say—can render a socioeconomic measure wrong. Perhaps an education measure would be wrong only if it required you to steal, or kill a person, or commit some other grave act. Or perhaps any measure that required you to have 'one thought too many' would be wrong (e.g., an education-furthering measure that required 
you to consider not favouring your child's education over other children's (Williams 1981, 18)). And so on. (Or, perhaps what is 'wrong' always depends on one's alternatives, in which case slogan (2) transmutes into slogan (3). I include (2) to maintain neutrality between moral theories.)

These judgments are difficult. But we implicitly make them every day. And, importantly, the difficulty of these judgements does not grant you discretion over their contents: we do not pick what we believe about right and wrong. (And even if you do, slogan (4) tells you how to pick, so you do not have discretion over the measure ultimately chosen.) Additionally, if you are reasonably unsure whether a measure is wrong, or if the measure falls in a vague zone between wrong and permissible, then the measure automatically fails slogan (2): (2) requires a reasonable belief that the measure would not be wrong. You need not settle all moral uncertainties before discharging your socioeconomic-consideration duties.

So much for slogan (2). Slogan (3) more sharply narrows down the field of potential Ms:

(3) For all $\mathrm{S}$ reasonably believes, if $\mathrm{S}$ took $\mathrm{M}$, this would realise no less expected value than would be realised if $S$ took any other measure open to $S$ for furthering this socioeconomic good.

Again, justice- and rights-violations might sharply diminish a measure's value, as might thoughts or actions that lack integrity. In addition, agent-relativity might come in here, in that cost-to-you might weigh more heavily in value assessments than cost-to-others. For example, if you're really not a people-person, then the education-furthering measure of volunteering at an adult education programme might have its value sharply diminished, compared to a similar 
measure for other agents - and, the measure might be more disvalued because this cost is a cost to you, rather than a similarly high cost to another person (Scheffler 1982).

Even after acknowledging these possible specifications of slogan (3), the slogan will remain controversial. This is because it assumes we can talk of measures having 'more' or 'less' expected value than one another. But this might not always be so, which leads us to slogan (4). Suppose you are weighing up two education-furthering measures. On one, you tutor disadvantaged children, with the opportunity cost of you having time to write a great novel. On the other, you send money to a child deworming charity, with the opportunity cost of you being able to buy some paints, which you would have used to paint a great painting. (Assume painting takes less time than writing.) Condition (3) might then be true of both measures. This might straightforwardly be because the measures are top-equal. But it might be because the novel and the painting are (epistemically or metaphysically) incommensurable (Raz 1986, ch. 13). How, then, should you choose? Ex hypothesi, neither measure is better than the other (if we're dealing with equality or metaphysical incommensurability), or is known to be better than the other (if we're dealing with epistemic incommensurability). So, if you were to exercise discretion—choosing on the basis of a whim or trivial preference-then you would disregard the value of the unchosen measure.

Given this, your obligation is to use a randomiser-a metaphorical equally-weighted dice with as many sides as there are top-ranked measures. In cases where it is indeterminate which measure is top-ranked, or where there is a tie, the use of a randomiser is the second stage of deliberation. It isn't external to your deliberative procedure, but rather the proper application of it in such cases. This is important: it removes your discretion or latitude entirely, so that there is one education-furthering measure, not chosen by you, that you owe to those whose education it furthers, that you wrong them by not performing, and that you may 
be threatened or coerced into performing-whether it's the tutoring or giving to the deworming charity. So we have the precise version of slogan (4):

(4) If two or more measures are reasonably believed to have highest equal expected value, or if the two or more highest-ranked measures are reasonably believed to have indeterminately comparable or incommensurable values, then $\mathrm{M}$ must be the measure selected by a randomised decision method that gives equal weight to each highestranked measure.

In sum, (1)-(4) are the deliberative means to discharging parts (A) and (B) of your socioeconomic consideration duties, which correlate to socioeconomic human rights. These conditions tell you which measure is M. Part (C) of your duty is to take M.

Two further points. First, M will very often involve taking individual steps towards coordinating with others to reform powerful collective agents, as implied in §II. The education example neglected this purely for exegetical simplicity. Second, while there may be value in reconsidering the four slogans periodically (and if so, this will be included in $M$ ), any measure that incorporated constant reconsideration would likely fail at slogan (3), since it would be too costly to the agent.

This gives determinate content to socioeconomic-consideration human rights, that is, rights that each agent conducts equitable deliberation and action for respecting, protecting, and promoting socioeconomic goods. And these rights are claimable:

For each socioeconomic good:

(i) each human is owed (A), (B), and (C) from every agent, so the agents wrongs those humans if the humans do not receive (A), (B), and (C); and 
(ii) the agents owes (A), (B), and (C) to the humans independently of specific institutional arrangements; and

(iii) each human (or his/her representative) may use threat or coercion to extract (A), (B), and (C) from the agents.

\section{Objections and Clarifications}

\section{IV.A Claimability}

These rights might seem unsatisfactorily claimable: I might never know if you have done your duty with regard to me, so never know that I am wronged, or what measure you owed, or that I might have used threats to extract it from you. However, notice that the same is true of civil-political rights-even rights to mere non-interference. Consider the right against arbitrary interference with one's privacy. If a detective snoops around my home without good reason, they've violated my human rights. But neither I, nor anyone else, might ever know about it. We do not think this makes the duty non-owed, makes me non-wronged, or leaves me unwarranted to demand redress for the snooping, if I find out. This problem will probably arise more often for socioeconomic-consideration human rights than for the civil-political rights. But this is a quantitative, not a qualitative, difference between them (Tasioulas 2007, 90-91).

A separate claimability-related problem is that these rights might seem not meet condition (iii): surely it's impermissible to threaten someone into including you in their deliberations about socioeconomic measures. To be sure, enforcing socioeconomicconsideration duties through law would potentially mean impermissibly invading individuals' private lives. The results would be unduly complex, costly, and inefficacious, and would potentially result in an insidious culture of blame and accusation against duty-bearers (O'Neill 2005, 436-9). However, it is never permissible to use disproportionate threats to 
enforce rights—-socioeconomic or civil-political, human or special. I will not take a stand on which threats are proportionate for enforcing socioeconomic consideration human rights. If John Stuart Mill is correct that negative public opinion and being berated by one's own conscious are a means of punishment, and if, therefore, the threat of these things is a form of coercion, then these might be appropriate means by which to coerce people into discharging these duties (Mill 1993[1861], 50).

One might reply with a third problem: what's the use of socioeconomic-consideration rights? If only minimal coercion is proportionate, then what will 'enforcing' them achieve? And if all we're enforcing is inclusion in deliberation, what's their political point? As Joel Feinberg put it, '[h]aving rights enables us to 'stand up like men,' to look other in the eye, and to feel in some way the equal of anyone." $(1970,252)$ The rights I have proposed do not enable this - or so the objection goes. If all I can demand of others, and blame them for not doing, is deliberating in a way that might lead them to act indifferently towards me, and if I can rarely permissibly back this up with force, then we have lost the political purpose of socioeconomic human rights. ${ }^{8}$

My reply is three-pronged. First, it would be nice if we could demand more of others, or demand it more forcibly, than I have proposed. But the claimability problem suggests this is not possible. Second, and more optimistically, all is not lost: if someone has not given you non-inequitable consideration, then they have not just done wrong. They have also wronged someone (specifically, you). This might mean you are owed any apologies, or that you (or your representative) is permitted to chastise them with a distinctive normative authority (not held by those who have not been wronged), or that they have failed in a duty whose content refers to you (Hayward 2013).

\footnotetext{
${ }^{8}$ I thank $*$ and $*$ for pressing this.
} 
Third, for many of those who lack socioeconomic goods, there is some agent not discharging the duties I propose: the government under which those individuals live. This is not true of all individuals, and governments are not the only ones who are failing (if these things were false, §II.A's argument would not work). But many individuals who lack socioeconomic goods can rightly complain that their government has inequitably deliberated, or has not furthered their socioeconomic goods as their deliberation demanded. Specific instances of such complaints would, of course, require substantive normative argument of the kind avoided here. But it's obvious that some governments have failed with regard to socioeconomic-consideration duties (North Korea, for example). So socioeconomicconsideration human rights do give people something to stand on, as long as they can cogently argue that their government should have taken some measure or other, which the government didn't take. Again, there's an analogy with civil-political rights: arguing that one's right to free association been violated requires evidence and argument, but this does not make the right politically impotent. Similarly, socioeconomic-consideration rights can be asserted politically.

A final claimability-related objection is that persons who lack adequate socioeconomic goods are not in a position to enforce this right, or to discharge its correlative duties. They are too busy trying to stay alive. It is a cruel joke to assert that people without adequate socioeconomic goods are permitted to enforce my duty to give them not-inequitable consideration. It's an even crueller joke to suggest they have a duty to reciprocate, by giving me not-inequitable consideration. Instead, socioeconomic goods are a precondition for someone's bearing the claims and duties of human rights, which can only properly include civil-political rights (since these do not concern the material goods necessary for right- and duty-bearing). ${ }^{9}$

\footnotetext{
${ }^{9}$ Conversation with $*$ inspired this objection.
} 
There are three options here. The first asserts that humans can be claimers without being claimees. I suspect this would not satisfy the objector, since the objection presupposes moral agency is necessary for making claims. The second agrees that some humans lack the requisites for making claims, and asserts that some agents (e.g., states) have (non-claimable, non-socioeconomic-consideration) duties to be the trustees of these persons, making claims on their behalf (Darwall 2006, 95; Scanlon 1998, 185-6). The second is to deny that socioeconomic goods are necessary for being a claimee or claimer. So those lacking such goods can both claim the duty and have it claimed of them. That said, the duty even to undertake the deliberation is only pro tanto-it can be overridden or outweighed by other moral and non-moral considerations. So those lacking adequate socioeconomic goods might not have an all-things-considered duty to undertake the deliberation.

\section{IV.B Practicality}

There are three practicality-related objections. The first arises from ongoing philosophical debates: about morality's demandingness; about what determines rights' importance; about the role of community and contribution in constraining our duties to humans worldwide; and so on. The objection is that this lack of consensus makes it impossible to determine whether I have discharged my socioeconomic-consideration duties, which means these duties cannot be what correlate to socioeconomic-consideration human rights. So, this objection contains two steps: from debates to impracticability, and from impracticability to inaccuracy.

On the first step: all duties correlative to human rights have ongoing debates about their constraints and content. There are debates about the right to life, for example, where this is understood as implying simply a duty not to kill. It's unclear whether killing is permitted if not intended but merely foreseen, whether there's a difference between killing and letting die, how to define the 'persons' bearing this right (foetuses, for example), whether this right is 
ever subject to aggregation (may I kill one to save fifty?), and, if aggregation is permitted, in what circumstances (may I kill one to save five? to save my child?). These debates make it tricky to know whether I have discharged the duty correlating to the right to life. Again, the difference here between socioeconomic-consideration duties and duties correlative to other human rights is one of quantity, not quality (Tasioulas 2007, 90).

A final point on the first step in this objection: it is often possible to judge that an agent is not fulfilling their socioeconomic-consideration duties. Anyone for whom it doesn't even cross their mind that they should consider doing something to help others enjoy socioeconomic goods is clearly reneging on this duty. There are many individual and collective agents like this. The fact that there are some blurry cases (is the affluent individual who donates $£ 20$ a month to effective charities discharging the duty-or would truly reasonable deliberation have led her to give $£ 50$ ?) does not undermine the practicality of assessing violations of socioeconomic-consideration human rights in all cases. We can make many certain judgments that people are not doing their duty, and some certain judgments that people are doing their duty, even if there are many borderline cases.

The second step in this objection - the move from impracticality of the duty to the inaccuracy of the duty-is much less potent. The fact that there is a lack of philosophical consensus on an issue (say, the extent of morality's demandingness) does not imply that there is no fact of the matter about that issue. This is true on both constructivist and realist conceptions of moral truth.

A second practicality-based objection re-launches the claimability problem, deriving from "ought' implies 'can". The idea is that-even if the philosophical debates were resolved-socioeconomic-consideration duties would be beyond the capacities of human agents: we cannot possibly evaluate the myriad upshots of each socioeconomic measure open to us. Because such knowledge is beyond human ken, we must simply pick a geographic, 
social, or political context, familiarise ourselves with that context, and take the measure that ranks highest for that context. If this is correct, then "[t]he fact that some agent chooses to devote their attention to contexts of political activity that do not directly concern my own plight does not constitute a directed wrong done to me." (Hope 2014, 18) In other words, if we must pick a context before we can begin our measure-ranking research, then the duty is not claimable.

First, notice that non-interference rights also face this objection. Not interfering can be surprisingly cognitively demanding (Lichtenberg 2004). When it is, this objection and my reply would apply. My reply, then, is that according to my proposal, it is not sufficient for the agent to simply 'pick' a context. The duty is to enact a procedure (slogans (1)-(4)), and then act as the procedure demands. If the agent is unable to determine in which context she should act, then she must give equal chance to each context, using a randomising procedure. So if one can only do research into one context, then the duty is to roll a dice, with a side for each context (the dice might be weighted to reflect the agent's beliefs, if any, about the value of acting in each context), then do research into the values of measures for whichever context the dice chooses, and take the measure with the most value for that context. By picking the context that the dice lands on, the agent does her duty. This duty does not contain discretion, and can be enacted for all, owed to all, and claimed by all.

The style of reply is anticipated by Hope. We might

insist that in choosing to engage in some relevant contexts of political activity, I am in fact fulfilling everyone's human rights to assistance ... Yet ... given that my actions cannot reach all who are suffering, talk of fulfilling their rights is likely to seem empty from the point of view of those in contexts of political activity I elect not to engage in. (2014, 18, emphasis original; similarly Woodward 1986, 809) 
However, we should consider the respect that is shown to each human by performing the deliberation, considered independently of the resultant action-even if the deliberation involves a randomiser. If someone lacking socioeconomic goods complains that I have violated their right, then I should explain the procedure I used to determine the measure I took, and explain that the claimant did not receive inequitable consideration in that procedure. They have a right that such an explanation be true and provided, but not a right to anything more. This account gives them much more than Hope's discretionary account does: on a view with discretion, if I am approached by someone lacking socioeconomic goods, then I may simply say that I didn't pick them. I had discretion, and I exercised it. But 'picking' doesn't reflect respect for the non-picked. Consideration does-even if that consideration was performed under physical limitations, so that some of the result was random.

A final objection asks how socioeconomic-consideration duties relate to all-thingsconsidered moral reasoning. It asks whether parts (A), (B), and (C) of socioeconomicconsideration duties - and slogans (1)-(4) that allow agents to ensure parts (A) and (B) are discharged-are just aspects of what we morally ought to do all the time, all things considered, when we're deciding what we morally ought to do in general. Perhaps the parts and slogans I've laid out apply to many—perhaps all—moral decisions, and so don't tell us anything in particular about socioeconomic goods or their associated human rights.

I'm not sure why such continuity is a bad thing. The more deeply we can embed socioeconomic human rights (and civil-political rights, for that matter) into the everyday moral deliberation of all agents—individual and collective_- the less human rights are viewed as something only the most powerful of agents need to consider in the most dire of circumstances. Instead, human rights become a problem for all agents to solve, all the time. My proposal embeds socioeconomic human rights into the rest of moral deliberation and 
action. This includes deliberation about civil-political human rights, the violation of which might be a wrong-making feature of socioeconomic measures. Such continuity between types of human rights, and between human rights and the rest of morality, seems like something to be celebrated, not resisted.

Questions remain. I have not demonstrated that my four proposed slogans for socioeconomic-consideration constitute the best structure within which to house socioeconomic-consideration human rights and their correlative duties. If other structures would work, then so much the better for socioeconomic-consideration human rights. There are also questions about which goods are 'socioeconomic'; how we differentiate amongst socioeconomic goods (and, therefore, amongst socioeconomic-consideration human rights); why some socioeconomic goods are valuable enough to generate socioeconomicconsideration duties; whether international intervention is justified if a state does not discharge its socioeconomic-consideration duties; how socioeconomic-consideration human rights stack up against other human rights; and so on. In short, I have not given a full positive case for the existence of socioeconomic-consideration human rights: I have merely saved them from the claimability objection, which, I have argued, is fatal to other construals of socioeconomic human rights. If the claimability objection has been answered, then we will be some way-but only some way-towards justifying and understanding socioeconomicconsideration human rights, that is, human rights that each agent conducts equitable deliberation and action for respecting, protecting, and promoting socioeconomic goods.

\section{References}

Ashford, Elizabeth. 2006. "The Inadequacy of our Traditional Conception of the Duties Imposed by Human Rights." Canadian Journal of Law and Jurisprudence XIX(2), 217-35. 
Beitz, Charles. 2003. "What Human Rights Mean.” Daedalus 132(1), 36-46.

Brownlee, Kimberley. 2013. "A Human Right Against Social Deprivation." The Philosophical Quarterly 63(251), 199-222.

Cabrera, Luis. 2004. Political Theory of Global Justice: A Cosmopolitan Case for the World State. London: Routledge.

Chappell, Timothy (ed.). 2009. The Problem of Moral Demandingness: New Philosophical Essays. London: Palgrave Macmillan.

Collins, Stephanie. 2013. Collectives' Duties and Collectivization Duties. Australasian Journal of Philosophy, 91/2: 231-248.

Cranston, Maurice. 1962. Human Rights Today. London: Ampersand Books.

Darwall, Stephen. 2006. The Second-Person Standpoint. Cambridge, MA: Harvard University Press.

Feinberg, Joel. 1970. “The Nature and Value of Rights.” Journal of Value Inquiry 4(4), 243260.

Feltham, Brian and John Cottingham (eds). 2010. Partiality and Impartiality: Morality, Special Relationships, and the Wider Word. Oxford: Oxford University Press.

French, Peter A. 1979. "The Corporation as a Moral Person." American Philosophical Quarterly 16(3), 207-215.

Gilabert, Pablo. 2009. “The Feasibility of Basic Socioeconomic Human Rights: A Conceptual Exploration." The Philosophical Quarterly 59(237), 659-81.

Gilabert, Pablo. 2010. "Kant and the Claims of the Poor." Philosophy and Phenomenological Research LXXXI(2), 382-418.

Griffin, James. 2008. On Human Rights. Oxford: Oxford University Press.

Hayward, Tim. 2013. “On Prepositional Duties.” Ethics 23(2), 264-91. 
Hope, Simon. 2014. "Kantian Imperfect Duties and Modern Debates over Human Rights." Journal of Political Philosophy 22(4), 396-415.

Kuper, Andrew. 2000. "Rawlsian Global Justice: Beyond the Law of Peoples to a Cosmopolitan Law of Persons." Political Theory 28 (5): 640-74.

Lawford-Smith, Holly. Forthcoming. "What 'We'?” Journal of Social Ontology.

Lichtenberg, Judith. 2004. "Negative Duties, Positive Duties, and the 'New Harms'." Ethics 120(3), 557-578.

List, Christian and Philip Pettit. 2011. Group Agency. Oxford: Oxford University Press.

Locke, John. 1689. Two Treatises of Government. Awnsham Churchill.

Meckled-Garcia, Saladin. 2013. "Giving Up the Goods: Rethinking the Human Right to Subsistence, Institutional Justice, and Imperfect Duties." Journal of Applied Philosophy 30(1), 73-87.

Mill, John Stuart. 1993 [1861]. Utilitarianism. In Geraint Williams (ed.), Utilitarianism. London: Everyman.

Nickel, James. 1987. Making Sense of Human Rights. Berkeley: University of California Press.

Nickel, James. 1993. "How Human Rights Generate Duties to Protect and Provide." Human Rights Quarterly 15(1), 77-86.

Nickel, James. 2005. "Poverty and Rights.” The Philosophical Quarterly 55(220), 385-402.

Nussbaum, Martha. 2004. "Beyond the Social Contract: Capabilities and Global Justice." Oxford Development Studies 32(1), 1-18.

Office of the High Commissioner for Human Rights (OHCHR). 2015. "Key concepts on ESCRs - Are economic, social and cultural rights fundamentally different from civil and political rights?" Available at 
http://www.ohchr.org/EN/Issues/ESCR/Pages/AreESCRfundamentallydifferentfromciv ilandpoliticalrights.aspx.

O’Neill, Onora. 2005. “The Dark Side of Human Rights.” International Affairs 81, 427-439.

O’Neill, Onora. 2000. Bounds of Justice. Cambridge: Cambridge University Press.

O’Neill, Onora. 1996. Towards Justice and Virtue: A Constructive Account of Practical Reasoning. Cambridge: Cambridge University Press.

Pettit, Philip. 2007. "Responsibility Incorporated.” Ethics 117, 141-201.

Pogge, Thomas. 1992. "Cosmopolitanism and Sovereignty.” Ethics 103 (1): 48-75.

Pogge, Thomas. 2002. World Poverty and Human Rights. Cambridge: Polity Press.

Raz, Joseph. 1986. The Morality of Freedom. Oxford: Oxford University Press.

Scanton, T.M. 1998. What We Owe to Each Other. Cambridge, MA: Harvard University Press.

Scheffler, Samuel. 1982. The Rejection of Consequentialism. Don Mills: Oxford University Press.

Sen, Amartya. 2004. "Elements of a Theory of Human Rights." Philosophy and Public Affairs 32(4), 315-56.

Shue, Henry. 1996. Basic Rights: Subsistence, Affluence and US Foreign Policy. Second edition. Princeton: Princeton University Press.

Steiner, Hillel. 2006. "Self-ownership and Conscription." In The Egalitarian Conscience: Essays in Honour of G.A. Cohen, Christine Sypnowich (ed.), Oxford: Oxford University Press.

Stemplowska, Zofia. 2009. "On the Real World Duties Impose on Us by Human Rights.” Journal of Social Philosophy 40(4), 466-87.

Tasioulas, John. 2012. "On the Nature of Human Rights.” In G. Ernst and J-C Heilinger (eds), The Philosophy of Human Rights. Berlin: de Gruyter. 
Tasioulas, John. 2010. “Taking Rights out of Human Rights.” Ethics 120(4), 647-78.

Tasioulas, John. 2007. “The Moral Reality of Human Rights.” In T. Pogge (ed.), Freedom From Poverty as a Human Right. New York: Oxford University Press and UNESCO.

Tomalty, Jesse. 2014. "The Force of the Claimability Objection to the Human Right to Subsistence." Canadian Journal of Philosophy 44(1), 1-17.

Waldron, Jeremy. 1993. Liberal Rights. Cambridge: Cambridge University Press.

Wenar, Leif. 2007. "Responsibility and Severe Poverty." In T. Pogge (ed.), Freedom From Poverty as a Human Right. New York: Oxford University Press and UNESCO.

Wendt, Alexander. 2004. "The State as Person in International Theory." Review of International Studies 30(2), 289-316.

Williams, Bernard. 1981. Moral Luck: Philosophical Papers 1973-1980. Cambridge: Cambridge University Press.

Woodward, James. 1986. “The Non-Identity Problem.” Ethics 96, 804-831.

Wringe, Bill. 2005. "Needs, Rights, and Collective Obligations." Royal Institute of Philosophy Supplement 57, 187-208.

Wringe, Bill. Forthcoming. "Collective Obligations: Their Existence, Their Explanatory Power, and Their Supervenience on the Obligations of Individuals." European Journal of Philosophy. 